\title{
Alguém mais belo do que eu: Alberto Caeiro, Leopold Bloom, o Portugal de Pessoa, a Irlanda de Joyce e outras Brancas de Neve
}

The Fairest Mirror of All: Alberto Caeiro, Leopold Bloom, Pessoa's Portugal and Joyce's Ireland

Quelqu'un de plus beau que moi: Alberto Caeiro et le Portugal de Pessoa, Leopold Bloom et l'Irlande de Joyce (et d'autres Blanche-Neige)

Inês Lage Pinto Basto

\section{OpenEdition}

\section{Journals}

Edição electrónica

URL: http://journals.openedition.org/rccs/925

DOI: $10.4000 /$ rccs. 925

ISSN: 2182-7435

\section{Editora}

Centro de Estudos Sociais da Universidade de Coimbra

Edição impressa

Data de publição: 1 Junho 2006

Paginação: 41-48

ISSN: 0254-1106

Refêrencia eletrónica

Inês Lage Pinto Basto, «Alguém mais belo do que eu: Alberto Caeiro, Leopold Bloom, o Portugal de Pessoa, a Irlanda de Joyce e outras Brancas de Neve », Revista Crítica de Ciências Sociais [Online], 74 | 2006, colocado online no dia 01 outubro 2012, criado a 22 abril 2019. URL : http:// journals.openedition.org/rccs/925; DOI : 10.4000/rccs.925 


\title{
Alguém mais belo do que eu: Alberto Caeiro, Leopold Bloom, o Portugal de Pessoa, a Irlanda de Joyce e outras Brancas de Neve
}

\begin{abstract}
Ao definir-se como um quarto de espelhos fantásticos, Fernando Pessoa encontra no espelho a única certeza comum a todas as "reflexões falsas", a materialização da "única anterior realidade" que os seus inúmeros espelhos "torcem". Tomando a Branca de Neve como uma sublimação final da beleza usurpadora da Madrasta e a corporização de uma beleza inicial, considerarei os "inúmeros espelhos fantásticos" de Pessoa e o "cracked looking glass" de Joyce como distorcidas sequelas de uma qualquer pureza de origem ou de uma superfície reflectora una. Argumento que Caeiro, Bloom, o Império Espiritual de Pessoa e a "Irlanda Caricatura do Mundo Sério" de Joyce virão a ser a materialização dessa superfície reflectora de origem, Brancas de Neve posteriores às realidades que lhes são madrastas mas colocadas estrategicamente na sua origem e destinadas a suprir a ausência de uma "única anterior realidade" - pessoal, nacional e global.
\end{abstract}

Sou como um quarto com inúmeros espelhos fantásticos que torcem para reflexões falsas uma única anterior realidade que não está em nenhuma e está em todas.

FERNANDo PESSOA

Por mais distante deste quarto que esteja o reino da Rainha Má - que há muito, muito tempo se olhava ao espelho até se ver destronada por uma espécie de versão desmalignizada de si mesma, por uma beleza usurpadora da sua realidade anterior - esta é ainda e de novo a história da Branca de Neve. Ou a história de uma Branca de Neve torcida para inúmeras reflexões falsas, o que é uma outra história.

Nesta outra história, tudo gira em volta da inexistência de uma "única anterior realidade" e tudo se desenrola a partir das "inúmeras reflexões falsas" que paradoxalmente reproduzem essa mesma inexistência e a "torcem”. Aqui a única personagem é o espelho. E é o espelho que diz a nova verdade: a de que, por não haver verdade e tudo serem reflexões falsas, só o espelho é verdade; ou a de que, à falta de outra realidade 
anterior, é ele, o espelho, superfície que em dedicação exclusiva se cumpre na eterna actividade de só espelhar, a "única anterior realidade" possível e plausível.

Em Pessoa e em Joyce a essência do sujeito, ou a da nação, ou a do mundo, funciona como uma inexistência que só através de uma pluralidade de reflexões torcidas e imperfeitas pode intuir-se. Assim, o espelho que em S. Paulo encobria o face a face $(1$ Cor 13,12) descobre-se já fragmentado, e é a esse espelho uno, anterior à fracção, que Pessoa e Joyce querem dar irónica (e fecunda) existência. A remoção do espelho que, no fim dos tempos, revelaria o Criador e revelaria a Criação é descartada, e é a arte, o supremo espelho, que passa a funcionar como uma espécie de "única anterior realidade" de substituição - pessoal, nacional, global e metafísica.

Nesta história só de espelhos, a Branca de Neve é este espelho uno - que tanto se estabelece como objecto primeiro, anterior a todas as "falsas reflexões", como se descobre reconstituição última de uma unidade ausente e a Madrasta surge desdobrada em inúmeros espelhos fantásticos, desordenada realidade plural que tanto precede o surgimento da nova beleza revelada como se descobre fragmentária desvirtuação, ou falsa mãe, dessa "única anterior realidade".

Quando, na história da Branca de Neve, o espelho mostra à beleza espelhada a existência, nas periferias do reino, de uma beleza pura, a Madrasta, que a precede no tempo, vê-se reduzida a uma distorcida reflexão da beleza benigna, legítima e infantil - ou benignizada, legitimada e infantilizada - que lhe é revelada.

É com a Rainha Má que esta história começa, ou começa com o espelho adulterado e fragmentado em inúmeros espelhos fantásticos, madrasta estéril que incessantemente procura em todas e em cada uma das suas retorcidas reflexões a beleza que lhe fugiu e se perdeu na cerração, uma qualquer beleza "original”, anterior ou alheia à desvirtuante pluralidade da especulação.

Assim, o espelho fragmentado ou o espelho-Madrasta, procura uma nova beleza que lhe seja "Branca de Neve" - simultaneamente, a causa da sua fragmentação e a corporização cabal, útil e libertadora da sua "única anterior realidade".

Ao partir em demanda desse princípio organizador insuportavelmente ausente, o espelho-Madrasta faz por encontrá-lo já cadáver - beleza anterior conservada em esfinge ou corpo que só em rigor mortis poderá autenticar a existência da sua inexistência. Mas o cadáver irá inesperadamente conhecer nova vida ao beijo alheio, anunciando-se imprevisivelmente fecundo. 


\section{O espelho português}

Sendo o "espelho" a única realidade concreta, material e visível capaz de presidir a todos os espelhos e de estar e não estar em todas e em cada uma das reflexões falsas que o quarto de espelhos fantásticos que Pessoa diz ser projecta, é no facto de espelhar e de ser espelho, de se descobrir ficção de si mesmo - e esvaziado criador de ficções - que Pessoa encontra a sua unidade, a sua identidade, o seu princípio organizador, aquilo que, por aproximação exterior, poderá funcionar como a sua "única anterior realidade".

O sonho de espelhar límpida e integralmente, de ser simultaneamente espelho de origem anterior à fracção e novo espelho que reúne os fragmentos, é assim corporizado neste encoberto espelho-Branca-de-Neve que Pessoa se descobre. É este espelho que reproduz em versão virtuosa, una e fecunda, a beleza desvirtuada e estéril do fragmentário espelho-Madrasta. Estabelecendo-se a posteriori como corpo de origem, o espelho-Branca-de-Neve apresenta como consequência a pluralidade desvirtuada do Espelho-Madrasta, usurpando-lhe e sublimando-lhe a beleza originária.

O facto de Pessoa se querer cumprir só como espelho, e de não poder (ou não querer) encontrar a sua "única anterior realidade" para além dele, coloca-o face a face com o espelho de S. Paulo, a que atrás me referi:

Agora vemos como num espelho e de maneira confusa; mas depois veremos face a face. Agora o meu conhecimento é limitado, mas depois conhecerei como sou conhecido. $(1$ Cor 13, 12)

Pessoa, que se não conhece a si mesmo senão por uma confusa pluralidade de reflexões falsas, estabelece o espelho como única existência visível e credível do "face a face" (a sua "única anterior realidade" como criador a tempo inteiro e a "única anterior realidade" do Criador). O espelho total que o separa de um Deus ignoto ou inexistente surge como a única verdade do transcendente ou do vazio, e o espelho que Pessoa se descobre aparece como a única unidade de fundo, a única porta fechada disponível para a "anterior realidade" de um desconhecido que se espelha - e que, de resto, tal como Deus ou como o carácter que Pessoa diz que talvez não tenha, pode bem não existir independentemente ou mesmo para além da realidade espelhada:

A minha perpétua atenção a mim perpetuamente me aponta traições de alma a um carácter que talvez eu não tenha. (Pessoa, s.d,a: 179)

Quando Álvaro de Campos protesta que lhe "puseram uma tampa - / Todo o céu”, é deste espelho, que é também um espelho ou uma tampa interior, 
que fala (Pessoa, 2002: 490). O céu funciona, em Pessoa, como a superfície exterior de uma inexistência, lápide ou cadáver de um Deus uno e de um sujeito essencial, esfinge que, no entanto, se mostra inesperadamente capaz de dar vida.

É esta ficção totalizante que encobre uma realidade primordial inexistente, esta tampa que tanto pode velar o "Nada" como o "Coisa Nenhuma", que Pessoa quer afirmar como princípio organizador e unificador de si mesmo e do mundo: é ela que, ao instituir-se como tampa a encobrir a origem da ficção, se estabelece, ela própria, como ficção de origem - acabando por prenunciar a ficção como origem.

Pessoa cria, com Caeiro, o seu incorrupto espelho-Branca-de-Neve, última tampa que separa um criador vazio da pluralidade que o reflecte ou que ele reflecte (a distinção permanece ironicamente indistinta). Assim, o pálido Caeiro é, simultaneamente, a brancura anterior às cores e a brancura que as contém a todas, o ser originário a quem Campos reconhece "uma argumentação cumulativamente feminina e infantil" e o inatingível culminar de tudo: espécie de alfa e de omega, suprema materialização em persona do carácter que Pessoa diz talvez não ter mas que os discípulos do espelho-Mestre - o próprio Pessoa e as suas outras falsas reflexões - sentem que traem e não atingem (Pessoa, s.d.,b: 174).

À imagem e semelhança de Caeiro, também o Portugal que abre a Mensagem se constrói como tampa estrategicamente colocada entre o fim do mundo conhecido e o "mar sem fim". O que era, em Caeiro, "natureza sem gente", é aqui desertificado recorte de costa, e o "olhar nítido como um girassol" do Mestre torna-se esfíngico vazio que fita, máscara de uma cabeça ibérica, Branca de Neve morta e ungida para o beijo. Dito de outra maneira, do Portugal amortalhado ressuscita o Portugal do Império Espiritual, tal como de Viriato, o pastor real que resistiu à poderosa investida do Império Romano e que foi traído pelos seus, ressuscita o Guardador de Rebanhos etéreos que o vem vingar ou cumprir espiritual ou poeticamente. Como a poesia e os heterónimos originados por Caeiro glosam e revelam o Mestre, também o "mar sem fim" onde "Deus espelhou o céu", o mar "do perigo e do abismo", espelho terreno do espelho celeste, revela ao mundo a tampa da sua "única anterior realidade": o Portugal fonte ou o Portugal-Branca-de-Neve perante o qual o mundo inteiro se descobre em toda a pluralidade dos seus "concretos absolutos".

É para o Portugal lápide exterior de um centro morto a partir do qual o mundo vário flui, para o Portugal que se oferece em esfinge para que o Mundo-Madrasta nele encontre a sua origem cristalizada ou o seu princípio organizador, que Pessoa tem reservado um futuro principesco. 
O imperialismo espiritual português é esse futuro principesco: a vida após a morte de um Portugal esfinge que repete e amplifica a fecundidade e a continuidade que Caeiro conhece - e Pessoa atrás dele - ao ver-se espelhado em "toda uma literatura". E este imperialismo espiritual vai, de novo, prefigurar-se como a "Branca de Neve" de todos os "falsos" imperialismos - que o imperialismo britânico, o imperialismo-Madrasta por excelência, supremamente representa, herdando do Império Romano todo o poder material. É face a face, ou espelho a espelho, com este "imperialismo-Madrasta" que Pessoa coloca o imperialismo espiritual português - que, uma vez mais, indistintamente se constrói a partir do britânico e o espelha em versão originária, "espiritual" e desmalignizada, embora distintamente se estabeleça como sua raiz ou como supremo detentor da "única anterior realidade" que o Império Britânico imperfeita e fragmentariamente reflecte.

Quando o espelho uno revela à Madrasta cruel a pura e sublimada verdade de si mesma, alguém mais belo, mais novo, alguém nascido de um sonho antigo que se move numa natureza sem gente, cantando ao desafio com os passarinhos e arrumando a casa aos anõezinhos numa eterna Primavera que a própria morte só vem contribuir para eternizar mais ainda, alguém que de alguma forma a antecede, a destrona e lhe irá sobreviver, a Rainha Má, que se julgava a mais bela, descobre-se realidade fragmentária e desvirtuada, vê-se amálgama de falsas reflexões dessa "única anterior realidade" que o espelho lhe mostra e que ela insanamente persegue sem nunca a conseguir plenamente atingir, acabando por precipitar-se no abismo. $\mathrm{Ou}$ assim o teria desejado Pessoa para o espelho total que ele mesmo se descobria, assim o desejara para Caeiro, e assim o desejaria para o império espiritual português, querendo-o princípio organizador da pluralidade, "única anterior realidade", intangível e inatingível mas actuante, em torno da qual esplenderia a secundarizada realidade de todos os falsos impérios - e de toda a realidade. $\mathrm{O}$ mesmo desejo que de outro modo expressaria num poema ortónimo, o reiterado desejo de ser a última tampa, a primeira e a derradeira ficção, o espelho colado à suprema ausência capaz de figurar o centro mudo e negro do girassol e de se descobrir estranhamente capaz de congregar e de irradiar vida:

\author{
Girassol do falso agrado \\ Em torno do centro mudo \\ Fala amarelo, pasmado, \\ Do centro negro, que é tudo. (Pessoa, s.d.,c: 56)
}


O centro negro e mudo do girassol a que Pessoa cola a pupila do Mestre, o centro que é tudo e em volta do qual se agitam, como heterónimos, as pétalas da uma realidade irremediavelmente plural, é o buraco negro em torno do qual gira toda a poesia pessoana, o vazio em torno do qual gira o mundo: a "única anterior realidade" que todas as pétalas torcem para reflexões falsas, aquilo que não existe mas que, no entanto, move a poesia que move o mundo.

\section{O espelho irlandês}

Stephen Dedalus define desde logo a Irlanda como "the cracked looking-glass of a servant" e prefigura-se ele mesmo como esse espelho fragmentado e contraditório, palco de inúmeras falsas reflexões, sem realidade anterior e interior unívoca e sem futuro vislumbrável (Joyce, 1986: 6). Leopold Bloom, que marca um retrocesso na cronologia anteriormente assente em Ulysses ao "nascer" às 8 da manhã numa cozinha de Dublin, é o espelho Branca-de-Neve que se vem antepor ou sobrepor a este espelho-Madrasta, é ele o espelho que se revela e que revela a Irlanda em nova versão simplificada, condensada e pacificada, estabelecendo-se simultaneamente como sua origem e como seu cumprimento último, simultaneamente como espelho anterior à fragmentação e como espelho aglutinador de todos os fragmentos.

Quando, em Ulysses, "A Irlanda Inteira" joga contra "O Resto da Irlanda" no Phoenix Park, é contraposta à totalidade oficial - "All Ireland" - toda uma outra equipa que se julgava inexistente - "The Rest of Ireland" -, equipa esta que vem pôr em causa a integridade da antiga totalidade. Bloom é depois identificado com esta equipa-Branca-de-Neve que destrona o monopólio da equipa-Madrasta quando, no mesmo capítulo de Ulysses, protesta: "All Ireland versus one!" (Joyce, 1986: 381 e 443).

É através deste elemento disruptivo, do inesperado surgimento, nas franjas do reino e do poder, desta "Branca de Neve", que em Ulysses se dá corpo à "única anterior realidade" que Bloom personifica e que, congregando o Resto da Irlanda, congrega o mundo inteiro: um mundo que a Irlanda Inteira ignorara e varrera de si mas que, depois de Joyce lhe o ter mostrado no espelho, descobria ancestral no seu próprio âmago. E uma Irlanda que o mundo ignorara e varrera de si mas que, depois de Joyce lhe a ter mostrado no espelho, descobria ancestral no seu âmago.

Bloom, o Ulisses duplamente baptizado segundo os ritos católico e protestante, o "anythingarian", o judeu não circuncidado que comia carne de porco, aquele que, para os dublinenses, não era "carne nem peixe", o que se deixava mansamente trair, a estranha novidade que se vinha antepor a 
Stephen, estabelecendo-se como seu pai simbólico e revelando-se a sua "única anterior realidade", o infinitamente tolerante e compreensivo Leopold Bloom, era a caricatura de uma Irlanda a cantar benignamente aos passarinhos - uma Irlanda pacificada (the rest of Ireland), espécie de inofensivo contra-poder que paciente, astuta e engenhosamente se sabia capaz de destronar e de sobreviver à Irlanda Inteira (que ele espelhava, mas que o passaria a espelhar).

Como acontece com o Caeiro de Pessoa, Bloom é um espelho que se mostra indissociável de uma identidade nacional totalizante e originante que Joyce também quer consagrar ao domínio exclusivo da arte - ou àquilo a que Pessoa escolheu chamar "o Império Espiritual" e a que agora se chama soft power.

Ao definir a Irlanda como "o país destinado por Deus para ser a eterna caricatura do mundo sério" - "a country destined by God to be the everlasting caricature of the serious world" (Joyce, 1996: 168) - Joyce repete, à escala global, o processo de subdivisão que tinha já aplicado ao sujeito poético (com Stephen e Bloom) e à própria Irlanda (com "All Ireland" e "The Rest of Ireland"), dividindo o mundo em Mundo Sério e Mundo Fictício ou Paródico, e reivindicando para a Irlanda ou para a sua arte o monopólio da ficção ou a prerrogativa de se cumprir única e exclusivamente como o caricatural espelho do mundo inteiro - ou como a "única anterior realidade" que o mundo inteiro caricaturalmente espelharia.

Pessoa e Joyce radicam-se e radicam as suas ficções totalizantes na certeza de que não há "única anterior realidade" independente da especulação, e de que todos os princípios organizadores da pluralidade são manifestamente "falsos", limitados, datados, localizados e estratégicos. Mas também se radicam na certeza da verdade destas mentiras, na convicção da misteriosa existência das inexistências a que escolhemos dar corpo e que assim se tornam capazes de libertar ou de oprimir, de regular ou de determinar, de inspirar ou de submeter, de criar ou de secar.

O miraculoso surgimento de Caeiro na vida de Pessoa, no dia 8 de Março de 1914, e o inesperado nascimento de Leopold Bloom aquando de um súbito retrocedimento na cronologia anteriormente assente no dia de Ulysses são indissociáveis do Portugal que tardiamente se revela como origem do mundo e da Irlanda que antecipadamente se oferece como sua caricatura. Ou da ficção que tardiamente se revela como origem do mundo, da nação e do sujeito, e da ficção que antecipadamente se oferece como caricatura do mundo, da nação e do sujeito. Ou ainda da ficção como origem e caricatura de si mesma. 
Com Caeiro, Bloom, o Portugal de Pessoa e a Irlanda de Joyce é-nos dado um berço-jazigo estrategicamente humilde, infantil e benigno, caixão onde jaz, velada por anõezinhos e passarinhos, uma Branca de Neve à espera do beijo da ressurreição ou de um final feliz que vingue a humilhação, a infantilização e a benignização a que a realidade madrasta a votara.

Acrescentando um último par de torcidas Madrastas e de retorcidas Brancas de Neve a estas reflexões, termino com uma breve especulação:

Também "o modernismo", e mesmo "os modernismos" - como entidades inexistentes, unas, aglutinadoras e originantes a que inúmeras reflexões vão dando existência - se podem estabelecer como cruéis Brancas de Neve que a seu bel-prazer vão entronando, destronando e condenando os modernismos mais incautos e inocentes à categoria madrasta de "reflexões falsas" (até que algum outro "modernismo" ou "modernismos" lhes venha apanhar os restos e queira branqueá-los).

$\mathrm{Na}$ arte - e na crítica - onde predomina o soft power, também há inevitáveis interferências e reflexos confusos do hard power: é que, tal como Pessoa e Joyce bem o souberam, os impérios espirituais são espelho dos impérios materiais que os espelham. E não há Branca de Neve sem Madrasta nem Madrasta sem Branca de Neve - muito embora as haja boas e más, fecundas e infecundas, menos belas e mais belas (dependendo do que está, e do que não está, de quem está, e de quem não está, por trás delas).

\section{Referências bibliográficas}

Joyce, James (1986), Ulysses. Org. Hans Walter Gabler. London: Bodley Head.

Joyce, James (1996), "Ireland: Island of Saints and Sages", in Ellsworth Mason; Richard Ellmann (orgs.), The Critical Writings of James Joyce. Ithaca: Cornell UP.

Pessoa, Fernando (2002), Poesia de Álvaro de Campos. Org. Teresa Rita Lopes. Lisboa: Assírio \& Alvim.

Pessoa, Fernando (s.d.,a), Textos de intervenção social e cultural: A fiç̧ão dos heterónimos. Ed. António Quadros. Mem Martins: Europa-América.

Pessoa, Fernando (s.d.,b), "Evocação memorialista" por Álvaro de Campos. Poemas de Alberto Caeiro. Org. António Quadros. Mem Martins: Europa América.

Pessoa, Fernando (s.d.,c), "Guardo ainda, como um pasmo". Poesia II 1930-1933.

Org. António Quadros. Mem Martins: Europa-América. 